\title{
Case Report of Epidermoid Cyst of the Testis and Review of Its Typical Imaging Features
}

\author{
Boutakioute $\mathrm{B}^{1^{*}}$, Sarf $\mathrm{I}^{2}$, Rais $\mathrm{H}^{3}$, Ouali $\mathrm{M}^{1}$, Cherif Idrissi El Ganouni $\mathrm{N}^{1}$
}

${ }^{1}$ Department of Radiology, Mohamed VI Hospital of Marrakech, University of Cadi Ayad Marrakech, Morocco

${ }^{2}$ Department of Urology, Mohammed VI University Hospital, University of Cadi Ayad Marrakech, Morocco

${ }^{3}$ Department of Pathology, Mohammed VI University Hospital, University of Cadi Ayad Marrakech, Morocco

DOI: $10.36347 /$ sjmcr.2020.v08i02.029

| Received: 10.02 .2020 | Accepted: 19.02.2020 | Published: 25.02 .2020

*Corresponding author: Badr Boutakioute

Abstract

Testicular epidermoid cysts are rare, benign intratesticular neoplasms. Preoperative diagnosis can be evoked by ultrasound and MRI, which are important criteria for the selection of testicular-preserving operations. In this paper, we report a case of a 21-year-old man who complained of a painful left testicular mass, which was found firm, regular, with a regular surface in examination. All laboratory investigations, including tumor markers, were normal. On ultrasonography, this mass appeared as a well-defined hypoechoic heterogeneous and avascular intratesticular lesion. On MRI, it was described as low signal T1 and heterogeneous hyper signal T2 lesion, surrounded by a capsule in hypo signal T1 and T2, enhanced after injection of Gadolinium, without perilesional oedema. Cyst enucleation cure was performed without postoperative complications. Histological diagnosis was an epidermoid cyst of the testis. A review of the literature has allowed us to highlight the different sonographic and MR imaging findings of testicular epidermoid cysts.

Keywords: Epidermoid cyst, intratesticular tumor, ultrasound, MRI, onion-skin apperance

Copyright @ 2020: This is an open-access article distributed under the terms of the Creative Commons Attribution license which permits unrestricted use, distribution, and reproduction in any medium for non-commercial use (NonCommercial, or CC-BY-NC) provided the original author and source are credited.

\section{INTRODUCTION}

Testicular epidermoid cysts are rare and benign masses, which have a frequency of around $1-2 \%$ of all resected testicular masses, but they are also the most common benign tumors originating in the testis [1]. In general, the most of patients present with enlarged testicle without any clinical symptoms [2]. Epidermoid cysts are benign lesions with no malignant potential [3] and can be cured by orchiectomy or enucleation of the lesion [3, 4]. However, many surgeons still favor orchiectomy rather than enucleation because sonographic findings are not specific and cannot accurately differentiate the lesions from testicular malignancies. Therefore, if sonography does not show specific findings compatible with testicular epidermoid cysts, an additional study by MRI can be used to confirm the diagnosis. This paper presents a case of an epidermoid cyst of the testis with a review of sonographic and MRI findings necessary for accurate preoperative diagnosis, which will guide the urologist to a conservative treatment.

\section{Case Report}

W. A., aged 34, was admitted to the urology consultation for a mild painful left scrotal mass for more than six months. He didn't have any systemic disease, history of urinary tract infection or history of recent trauma. The physical examination indicated the presence of a hard, regular, and non-inflammatory left mid-testicular mass measuring $3 \mathrm{~cm} \times 2 \mathrm{~cm}$, with a mild pain. All laboratory investigations, involving tumor markers were normal. A scrotal ultrasound with Doppler was performed, which revealed a $3 \times 2 \times 3 \mathrm{~cm}$ well-circumscribed hypoechoeic and heterogenic intratesticular mass with a discontinuous echogenic rim (Fig. 1a). No blood flow to the mass was detected by the Doppler ultrasound imaging (Fig. 1b). On MRI imaging (Fig. 2), the mass was described as a low signal T1 (Fig2a) and heterogeneous hyper signal T2 lesion (Fig. 2b), surrounded by a low-signal-intensity rim. On contrast-enhanced images, the lesion was sharply demarcated low-signal mass, with no internal enhancement (Figs. 2c). The patient underwent enucleation of the mass through a left inguinal incision. An extemporaneous examination was interpreted, and the regular pathological examination showed an 
epidermoid cyst and no evidence of malignancy. Enucleation of the lesion was then performed. The postoperative history was simple. The final pathology report stated that the mass was an epidermoid cyst without teratomatous elements (Fig. 3).

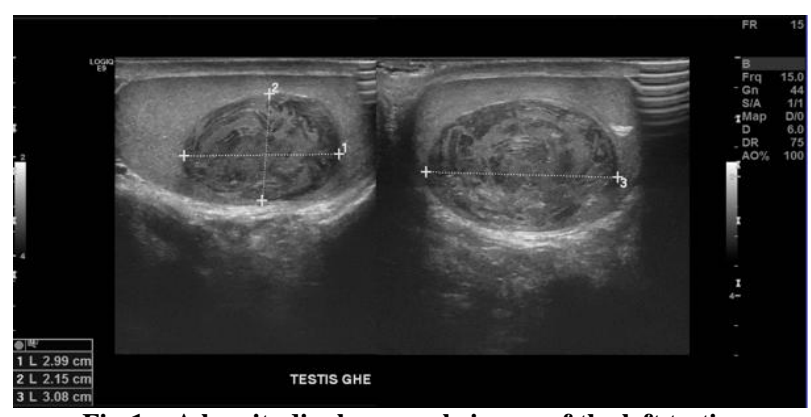

Fig-1a: A longitudinal grayscale image of the left testis demonstrating a hypoechoic heterogenous mass measuring $3 \times 2 \times 3 \mathrm{~cm}$, with normal-appearing surrounding testicular tissue

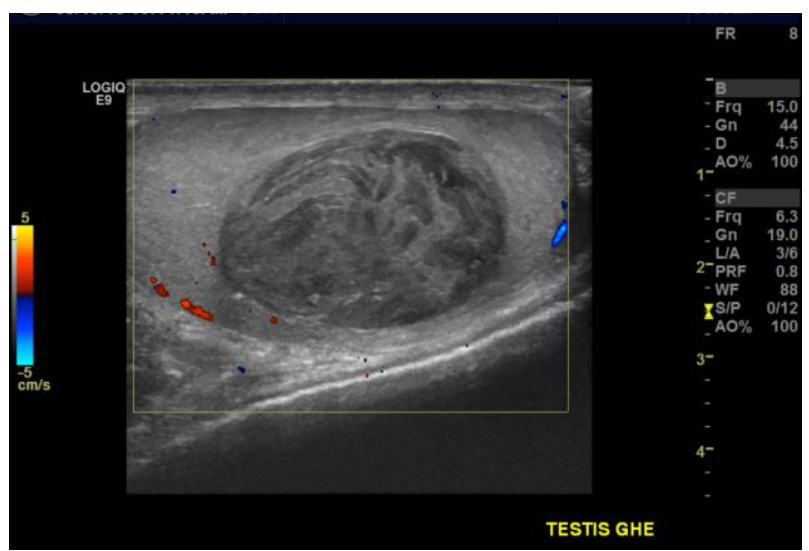

Fig-1b: A longitudinal color Doppler image of the left testis demonstrating the absence of internal vascularity within the mass and normal blood flow in the surrounding testicular parenchyma

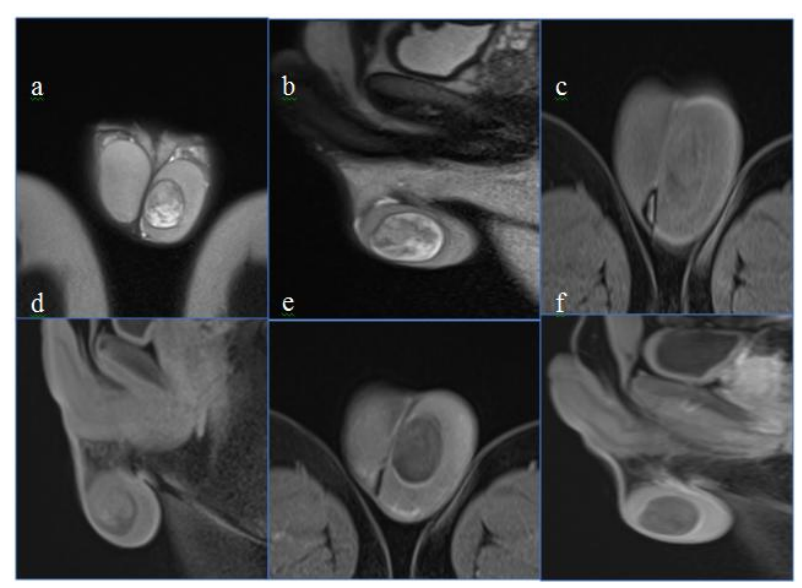

Fig-2: Scrotal MRI showing a simple left testicular epidermoid cyst

(a) coronal and (b) sagittal $\mathbf{T} 2$-weighted imaging showing a well-defined lesion of heterogeneous signal intensity intermixed with high, intermediate, and low signal intensities.,

(c) axial and (d) sagittal Unenhanced T1-weighted imaging showing a lesion of heterogeneous low signal intensity than testicular parenchyma, with partially indistinct margin.

(e) axial and (f) sagittal Fat-suppressed contrastenhanced T1-weighted imaging showing sharply marginated low-signal-intensity mass without enhancement.

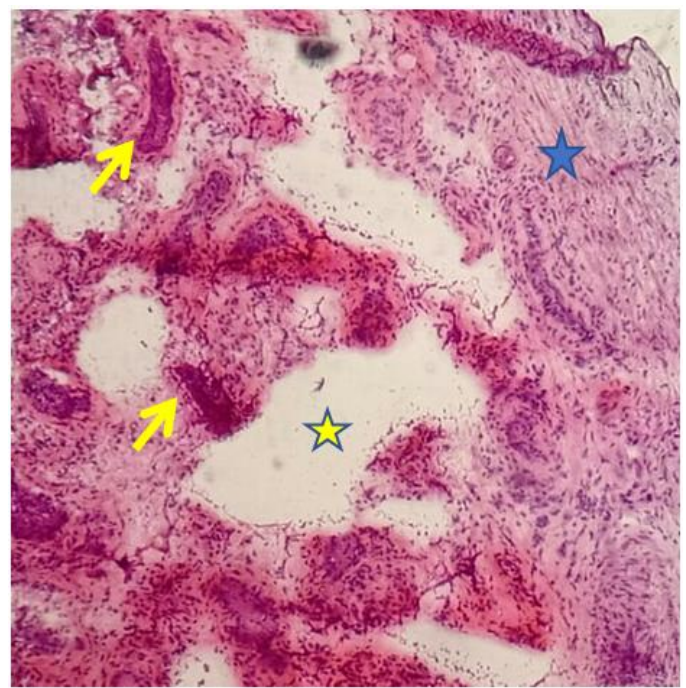

Fig-3: H\&E $\times 100$ epidermoid cyst of the testis lined by squamous epithelium with a granular layer, fibrous wall and lamellar keratinization in the lumen

- Regular coating squamous epithelium.

- Cystic component.

- The seminiferous tubules.

\section{DISCUSSION}

Testicular epidermoid cysts are rare benign lesions of the testis [5]. These lesions are more common in non-white men and their second and third decade of life [3-6]. Epidermoid cyst of the testis accounts for about $1 \%-2 \%$ of all testicular masses [7]. Therefore, there are no studies in the literature with a high number of patients. The majority of studies in the literature are in the form of case reports and there are a limited number of studies with long-term follow-up results. The histogenesis of testicular epidermoid cysts has not been completely proved, but most investigators suggest that these tumors are a monodermal development of a teratoma [1] or a squamous metaplasia of the seminiferous epithelium or rete testis. Its etiological origin has not been elucidated yet. Epidermoid cysts are benign lesions with no risk of malignant transformation, but they can reach very large diameters, causing damage to, or displacement of adjacent organs [8]. Testicular epidermoid cysts can be seen in childhood as well as in adults. Wu et al. [9] reported a patient with testicular epidermoid cyst who was 3 months old at diagnosis. In adults, cases are more commonly diagnosed in the second and third decades. In our case, the results were consistent with literature. Most patients are asymptomatic and scrotal pain, scrotal swelling, painless mass or a combination of these symptoms may be found in the medical history [10]. Testicular 
epidermoid cysts cannot be clinically distinguished from other testicular tumors. Because testicular epidermoid cysts are benign, a cure is possible if the mass is completely resected. Recently, organ-preserving surgery has become favored over traditional inguinal orchiectomy because it may offer better psychologic and cosmetic results and the preservation of fertility. Although organ preserving surgery has been widely advocated, many surgeons still carry out an orchiectomy because of the relatively high incidence of malignant testicular masses, the potential for misdiagnosis on frozen sections, and the possible existence of concurrent malignant lesions. But the most important problem is that the exact preoperative differential diagnosis is difficult. Sonography can suggest an epidermoid cyst, but it is often not sufficient to convince surgeons that the mass is an epidermoid cyst. Heidenreich et al. [4] reported that the sonographic appearance was not specific and inguinal testicular exploration was required. However, if an exact preoperative imaging diagnosis is possible, organpreserving surgery may be carried out more often. Sonographic findings of epidermoid cysts vary, but some suggestive findings have been described, and these correlate well with the gross pathologic findings [11]. Testicular epidermoid cysts are well demarcated from surrounding normal parenchyma by an echolucent or echogenic rim. Pathologically, the cyst is lined by a complete or incomplete inner lining of squamous epithelium. Also, a fibrous capsule with or without calcification or ossification may be present [12-15]. Langer et al. [15] found that the lesions with an echogenic rim had a fibrous capsule without calcification, and the lesions without an echogenic rim had an outer lining composed only of squamous epithelium. However, other investigators $[13,14]$ found that the echogenic rim represented calcification. On pathologic correlation of our case, the echogenic rim represented a fibrous capsule. The internal echogenicity may vary depending on the complexity of the internal contents. However, some cases show the specific finding of an onionskin [12, 15] or target [16] appearance of concentric rings of alternating hypoechogenicity and hyperechogenicity. The sonographic finding of alternating layers is pathologically well correlated with alternating layers of compacted keratin and loosely dispersed desquamated squamous cells $[3,12,15]$. Our case showed varying internal echogenicity, appearing as a merely heterogeneous mass. This complexity seems to be caused by the difference of arrangement in alternating patterns. In the cases of regularly arranged alternating patterns, an onionskin or target appearance is present. Langer et al. [15] described a lack of internal vascularity as another feature that can differentiate epidermoid cysts from most solid intratesticular lesions. Our case did not show any internal flow signal, correlated well with the results of Langer et al. On MRI, testicular epidermal cysts are described as highintensity, well-defined solid masses surrounded by a low-signal capsule on T2-weighted imaging [17]. Langer et al. [15] and Kondo et al. [18] showed that on T1-weighted MR images, some lesions had low signalbased, center with spotty high signal ("target" sign) and on T2-weighted MRI, some lesions had a laminated appearance, with alternating low and high signal intensity areas ("onion skin" sign). Although MRI is not routinely performed in our practice, we found the same findings in our patient. In addition, although epidermoid cysts have typical findings, it is not always possible to distinguish them from other scrotal lesions. Testicular germ cell tumors, testicular teratomas, dermoid cysts, tuberculosis and focal testicular hemorrhage should be considered in radiological differential diagnosis. A few reports of contrast-enhanced MR imaging of epidermoid cysts has been published [7, 10]. In this reports, the researchers performed contrast studies that did not show enhancement. This is well correlated with our result that showed no enhancement in our patient. No enhancement on contrast-enhanced MR imaging was well correlated with the results of color Doppler sonography. It may be a useful finding to differentiate epidermoid cysts from other solid intratesticular lesions.

\section{CONCLUSION}

Sonographic findings of a markedly heterogeneous intratesticular mass with or without alternating hypo- and hyperechoic layers surrounded by a hypoechoic or echogenic rim and the absence of flow on color Doppler sonography suggest the preoperative diagnosis of testicular epidermoid cysts. T2-weighted MR imaging findings of a high-signal intensity mass with or without low-signal-intensity foci surrounded by a low-signal-intensity rim and the absence of enhancement on contrast-enhanced T1-weighted MR images can strengthen the preoperative diagnosis. These imaging findings can offer a basis for surgeons to attempt testis-sparing surgery instead of orchiectomy.

\section{REFERENCES}

1. Price EB. Epidermoid cyst of the testis: a clinical and pathological analysis of 69 cases from the testicular tumor registry. J Urol. 1969;102:708-713

2. Hricak H, Hamm B, Kim BH. Testicular tumors and tumorlike lesions. In: Hricak H, Hamm B, Kim $\mathrm{BH}$, eds. imaging of the scrotum: textbook and atlas. New York: Raven. 1995:49-93

3. Dieckmann KP, Loy (badr) V. Epidermoid cyst of the testis: a review of the clinical and histogenetic considerations. Br J Urol. 1994;73:436-441

4. Heidenreich A, Engelmann UH, Vietsch HV, Derschum W. Organ preserving surgery in testicular epidermoid cysts. J Urol. 1994;153:11471150

5. Chen ST, Chiou HJ, Pan CC, Shen SH, Chou YH, Tiu CM, Wang HK, Lai YC, Lin YH, Wang J and Chang, CY. Epidermoid Cyst of the Testis: An Atypical Sonographic Appearance. Journal of Clinical Ultrasound.2016; 44, 448-451. 
6. Malek RS, Rosen JS and Farrow GM. Epidermoid Cyst of the Testis: A Critical Analysis. British Journal of Urology.1986; 58, 55-59.

7. Cho JH, Chang JC, Park BH, Lee JG and Son CH. Sonographic and MR Imaging Findings of Testicular Epidermoid Cysts. AJR American Journal of Roentgenology. 2002; 178, 743-748. https://doi.org/10.2214/ajr.178.3.1780743

8. Fakhir B, Mamouni N, Bouramdane N, Bouchikhi C, Bouguern H, Chaara H, Melhouf $\mathrm{M}$ and Banani A. A Rare Case of a Giant Pelvic Retroperitoneal Epidermoid Cyst. Libyan Journal of Medicine.2009; 4, 61.

9. Wu D, Shen N, Lin X and Chen X. Prepubertal Testicular Tumors in China: A 10-Year Experience with 67 Cases. Pediatric Surgery International.2018; 34, 1339-1343.

10. Loya AG, Said JW and Grant EG. Epidermoid Cyst of the Testis: Radiologic- Pathologic Correlation. RadioGraphics. 2004; 24, S243-S246.

11. Fu YT, Wang HH, Yang TH, Chang SY, Ma CP. Epidermoid cysts of the testis: diagnosis by ultrasonography and magnetic resonance imaging resulting in organ-preserving surgery. $\mathrm{Br} \mathrm{J}$ Urol. 1996;78:116-118

12. Malvica RP. Epidermoid cyst of the testicle: an unusual sonographic finding. AJR. 1993;160: $1047-1048$
13. Cohen EL, Carr L, Mandel E, Feigin G, Goodman JD, Dikman S. Epidermoid cyst of testicle: ultrasonographic characteristics. Urology. 1984; 24:79-81

14. Bahnson RR, Slasky BS, Ernstoff MS, Banner BF. Sonographic characteristics of epidermoid cyst of testicle. Urology. 1990;35:508-510

15. Langer JE, Ramchandani P, Siegelman ES, Banner MP. Epidermoid cysts of the testicle: sonographic and MR imaging features. AJR. 1999;173: 1295 1299

16. Maxwell AJ, Mamtora H. Sonographic appearance of epidermoid cyst of the testis. J Clin Ultrasound. 1990;18:188-190

17. Su J, Jiang T, Liu $X$ and Zhai R. Diagnosis and Differential Diagnosis of Testicular Epidermoid Cyst with MRI. National Medical Journal of China.2014; 94, 2139-2142.

18. Kondo T, Kawahara T, Matsumoto T, Yamamoto Y, Tsutsui M, Ohtani M, Ohtaka M, Kumano Y, Maeda, Y, Mochizuki T, Mori K, Asai T, Kuroda S, Takeshima T, Hattori Y, Teranishi J, Miyoshi Y, Yumura Y, Yao M, Inayama Y and Uemura $\mathrm{H}$. Epidermal Cyst in the Scrotum Successfully Treated while Preserving the Testis: A Case Report. Case Reports in Oncology.2016; 9, 235240. 